Article

\title{
Trends of Heat Waves and Cold Spells over 1951-2015 in Guangzhou, China
}

\author{
Rong Zhang, Zhao-Yue Chen, Chun-Quan Ou * and Yan Zhuang * \\ State Key Laboratory of Organ Failure Research, Department of Biostatistics, Guangdong Provincial Key \\ Laboratory of Tropical Disease Research, School of Public Health, Southern Medical University, \\ Guangzhou 510515, China; rongzhang322@gmail.com (R.Z.); zhaoyue940521@gmail.com (Z.-Y.C.) \\ * Correspondence: ouchunquan@hotmail.com (C.-Q.O.); zhuangy179@126.com (Y.Z.); \\ Tel.: +86-20-6136-0456 (C.-Q.O.); +86-20-6136-0753 (Y.Z.); Fax: +86-20-6164-8319 (C.-Q.O. \& Y.Z.)
}

Academic Editor: Christina Anagnostopoulou

Received: 16 December 2016; Accepted: 7 February 2017; Published: 14 February 2017

\begin{abstract}
The global climate has changed significantly, characterized by the warming of the surface air temperature, which seriously affects public health. We examined the trends of extreme temperatures, heat waves and cold spells in a subtropical city of Guangzhou, China, during 1951-2015. Specifically, the relationship between ENSO (El Niño-Southern Oscillation) events and heat waves/cold spells was discussed. The results of linear regression showed the annual mean temperature and extreme warm days increased $\left(0.14{ }^{\circ} \mathrm{C} /\right.$ decade and 6.26 days/decade) while extreme cold days decreased significantly (1.77 days/decade). Heat waves were more frequent, longer lasting and had stronger intensity over the past 65 years. In addition, the frequency, duration and intensity of heat waves were correlated with annual Atlantic Multi-decadal Oscillation (AMO) and Indian Ocean Basin-wide Warming (IOBW), while there were no significant differences in the characteristics of heat waves among an El Niño year, a La Niña year and a Neutral year. In contrast, neither significant trend nor association with ENSO events was observed for cold spells. In conclusion, our study indicated an obvious increasing trend for all aspects of heat waves in Guangzhou, China.
\end{abstract}

Keywords: extreme temperatures; heat waves; cold spells; ENSO events; Guangzhou

\section{Introduction}

The Earth's climate system has undergone tremendous changes since the early days of industrialization, some of which were due to human activities [1]. As a result, the global climate has changed significantly, characterized by the warming of the surface air temperature over the last 100 years or so, with an approximate increase of $0.85^{\circ} \mathrm{C}\left(0.65-1.06{ }^{\circ} \mathrm{C}\right)$ in global average combined land and ocean temperatures during the period 1880-2012 [1]. Particularly, it has been observed that the frequency, duration and intensity of heat waves have increased in some regions, leading to significantly adverse impacts on economy, agriculture and public health [2-4]. Furthermore, scenario-based projection research indicates that global averaged surface temperature is projected to increase by 1.4 to $5.8^{\circ} \mathrm{C}$ over 1990 to 2100 [5], which may increase future heat-related morbidity and mortality [3-6].

While extreme warm days increase, extreme cold days may decrease [7]. There is increasing evidence that the global warming is very likely attributable to anthropogenic increases in greenhouse gas (GHG) concentrations. Human influence has altered sea level pressure patterns globally [1]. Both GHGs and stratospheric ozone depletion have contributed to the observed poleward shift of the southern Hadley Cell border and the positive trend in the Southern Annular Mode in Austral summer [8]. The changes in the broad-scale circulation patterns have an important impact on regional temperature conditions [9-11]. A number of studies have shown that the rate of warming varies 
by region, climate and study period, and different measures of temperature extremes may present different trends [12-15]. For example, the frequency of extreme cold temperatures showed a statistically significant decrease, but the increase in extreme warm temperatures was not statistically significant in Toronto probably because the statistical power was limited as a result of the relatively short period of 30 years (1971-2000) [12]. The trends in number, total days, mean duration days of heat waves for 1951-2008 increased more significantly than 1971-2008 in Australia [13]. In India, the frequency of cold nights decreased considerably over 1969-2005 and the trends in the number of warm days increased significantly only in the interior peninsula $[7,14,15]$. In western Eurasia, a rapid increase in regional heat waves was observed since 2010, which was associated with the increasing frequency of large-scale, quasi-stationary positive centers of maximum height anomalies in the upper troposphere and the phase change of the Atlantic Multi-decadal Oscillation (AMO) $[9,16,17]$. The regional differences in historical trends of extreme temperatures need to take into account projected temperature increases under climate change scenarios and assessment of the impacts of climate change. In order to provide a full picture of climate change to the public and politicians, more studies in different parts of the world are required and would help regional decision makers in planning adaptation strategies.

In mainland China, Hou el al. [18] reported the regional mean temperature increased by $0.14{ }^{\circ} \mathrm{C}$ per decade over 1961-2007 in East China. Moreover, Zhang et al. [19] reported that the increase in surface air temperatures occurred mainly in the northeast and the northwest over 1960-2005, while a decline was observed in the south. Ye et al. [15] also observed spatial variations of heat waves in China from 1961 to 2010 and found an increasing trend in the central part of South China. These changes have been linked with the El Niño-Southern Oscillation (ENSO) and atmospheric circulations in the East Asian summer monsoon (EASM) [20-22].

In this paper, Guangzhou, the capital city of Guangdong Province, which is the largest city of southern China and the third largest city in China, was chosen as the study area where extreme hot events are particularly serious because of typical subtropical climate and the urban heat island effect since the population increased from about 1 million in 1951 to 14 million in 2015. We examined the long-term trend of extreme temperatures, heat waves and cold spells in terms of frequency, intensity and duration over 1951-2015 and determined the potential association with ENSO events.

\section{Materials and Methods}

\subsection{Data Collection}

Daily temperature data in Guangzhou over 1951-2015 were collected from the China Meteorological Data Network [23], including daily maximum, mean and minimum temperature. Historical data of El Niño and La Niña episodes during the study period are available at the website of Climate Prediction Center of National Oceanic and Atmospheric Administration (NOAA) [24]. Monthly data of AMO and Indian Ocean Basin-wide Warming (IOBW) were downloaded from the website of the National Climate Centre $[25,26]$.

We defined extreme warm day by daily maximum temperature higher than the 90th percentile and extreme cold day by daily minimum temperature lower than the 10th percentile during the whole study period (1951-2015). These definitions have been widely used in previous studies [27-29]. However, there is no consistent definition of heat waves and cold spells in the literature given variations in regions and sectors. It is usually based on some specific quantities or absolute of temperature but also involves some complex definitions related to duration, intensity and persistence of extreme events. In this study, heat waves and cold spells were identified based on the definitions proposed by the Chinese National Bureau of Meteorology [27,30,31]. In short, a heat wave is defined by daily maximum temperature $\geq 35^{\circ} \mathrm{C}$ for three or more consecutive days. A cold spell is identified when daily mean temperature decreases by $10^{\circ} \mathrm{C}$ over $48 \mathrm{~h}$ that results in daily minimum temperature $\leq 5^{\circ} \mathrm{C}$. Daily mean temperature $\geq 12^{\circ} \mathrm{C}$ and daily minimum temperature $>5^{\circ} \mathrm{C}$ means the end of the cold spell. We calculated the number of heat waves/cold spells in each year from January to December. 
The maximum value of daily maximum temperature during a heat wave and the minimum value of daily minimum temperature during a cold spell were used as a measure of the intensity. In addition, a threshold of $\pm 0.5^{\circ} \mathrm{C}$ for the Oceanic Niño Index (ONI), calculated by the 3-month running mean of ERSST v4 SST anomalies in the Niño 3.4 region $\left(5^{\circ} \mathrm{N}-5^{\circ} \mathrm{S}, 120^{\circ} \mathrm{W}-170^{\circ} \mathrm{W}\right)$, was adopted when identifying an El Niño year, a La Niña and a Neutral year [32].

\subsection{Statistical Analysis}

Linear regression models of yearly data were constructed to detect the linear trend of the annual mean temperature and heat waves/cold spells. The trend was presented as changes per decade. Some previous studies suggested that heat wave activity is associated with an ENSO event [14,33]. During the study period of 1951-2015, 85 heat waves were identified in Guangzhou, among which 84 occurred in June-September and only one occurred in May. Therefore, for the analysis of the association between heat waves and ENSO events, we used the Oceanic Niño Index (ONI) in June-August (JJA) to identify an El Niño year, a La Niña and a Neutral year. As 14 cold spells during the study period occurred in December-February, all the cold spells were also stratified by an El Niño year, a La Niña and a Neutral year defined by the ONI in December-February (DJF) [32]. A one-way ANOVA (Analysis of Variance) test was used to compare the frequency, duration and intensity of heat waves/cold spells among El Niño years, La Niña years and Neutral years. Moreover, linear correlation analysis was used to explore the associations between the frequency, duration and intensity of heat waves/cold spells and AMO/IOBW. All analyses were conducted using R 3.3.1 (R, Auckland, New Zealand) and SAS 9.4 (SAS Institute Inc., Cary, CA, USA).

\section{Results}

Table 1 shows the summary statistics of daily temperature in Guangzhou, 1951-2015. The annual mean temperature was $22.07^{\circ} \mathrm{C}$ on average (range: $21.20^{\circ} \mathrm{C}-23.20^{\circ} \mathrm{C}$ ) with a statistically significant increasing linear trend of $0.14{ }^{\circ} \mathrm{C}$ per decade $(p<0.01)$ (Figure 1). Figure 2 shows a significant linear trend for both annual extreme warm days and annual extreme cold days. The number of extreme warm days increased by 6.26 days per decade, while the number of extreme cold days decreased at a rate of 1.77 days per decade.

Table 1. Summary statistics of average annual temperatures in Guangzhou, 1951-2015.

\begin{tabular}{cccccccc}
\hline Temperature Measures $\left({ }^{\circ} \mathbf{C}\right)$ & Mean & Min & $\mathbf{P}_{\mathbf{5}}$ & Median & $\mathbf{P}_{\mathbf{9 5}}$ & Max & SD \\
\hline Mean temperature $\left({ }^{\circ} \mathrm{C}\right)$ & 22.07 & 2.09 & 10.70 & 23.50 & 29.70 & 34.20 & 6.17 \\
Minimum temperature $\left({ }^{\circ} \mathrm{C}\right)$ & 18.94 & 0.00 & 7.30 & 20.60 & 26.40 & 30.40 & 6.32 \\
Maximum temperature $\left({ }^{\circ} \mathrm{C}\right)$ & 26.49 & 4.30 & 14.30 & 27.70 & 34.50 & 39.10 & 6.34 \\
\hline
\end{tabular}

$\mathrm{P}_{5}$ and $\mathrm{P}_{95}$ are the 5th and the 95th percentiles, respectively; SD: stands for standard deviation.

For the 85 heat waves observed in Guangzhou during the study period of 1951-2015, the mean duration of all heat waves was 4.12 days. The longest two heat waves occurred in August 1990 and in October 2000, which both lasted 13 days. The day of heat waves was 1 July 2004 with a maximum temperature of $39.10^{\circ} \mathrm{C}$. There was a statistically significant increase in annual frequency, total duration, maximum duration, mean duration and intensity of heat waves (Figures 3 and 4), with an increase of $0.50,2.27,0.83,0.52$ and 0.21 per decade, respectively $(p<0.01)$ Moreover, the result of ANOVA indicated that there were no significant differences in frequency, total duration, maximum duration, mean duration and intensity of heat waves among El Niño years and La Niña years and Neutral years ( $p=0.92,0.60,0.80,0.53$ and 0.40 , respectively).

The time series of AMO and the characteristics of heat waves are shown in Figure 5. We found significant linear correlations between annual AMO and the frequency, total duration, maximum duration, mean duration and intensity of heat waves with Pearson correlation coefficients of $0.64,0.61$, 
$0.53,0.50$, and 0.46 , respectively $(p<0.01)$. Similar correlations were observed between IOBW and the characteristics of heat waves, with Pearson correlation coefficients of $0.56,0.54,0.46,0.42$ and 0.36 , respectively $(p<0.01)$.

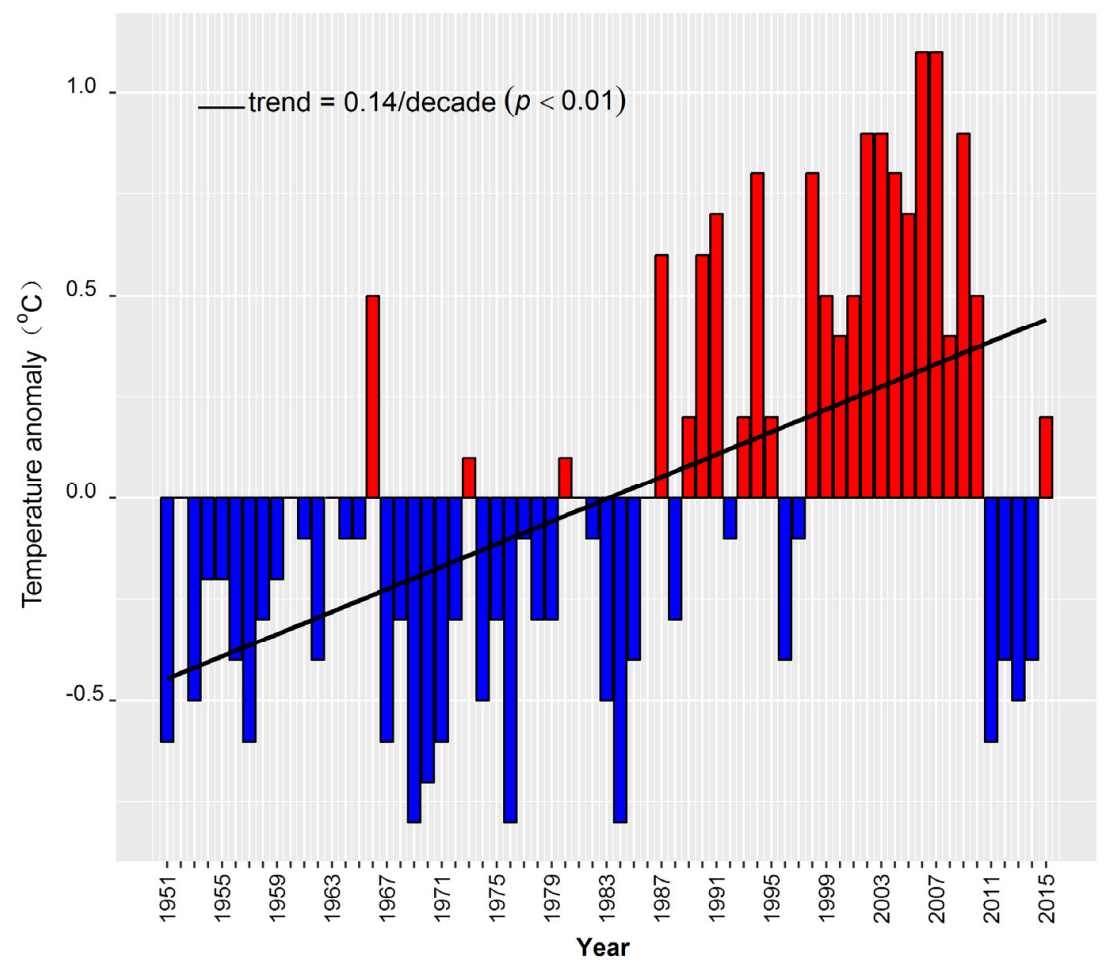

Figure 1. Variations of annual mean temperature anomalies in Guangzhou during 1951-2015. The line of $0{ }^{\circ} \mathrm{C}$ indicates that the annual mean temperature equals the average $\left(22.07^{\circ} \mathrm{C}\right)$ during the whole study period.

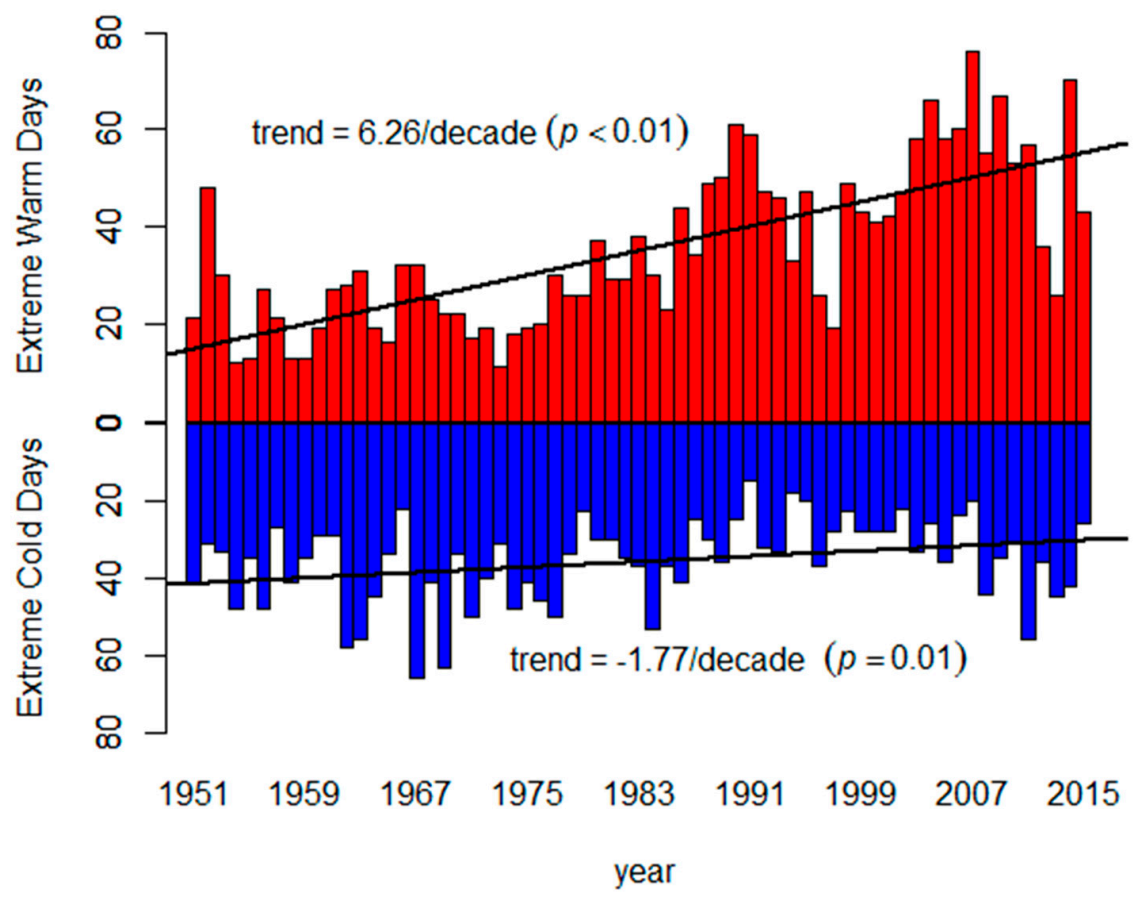

Figure 2. The number of extreme warm/cold days in Guangzhou over 1951-2015. The black lines indicate the linear trend. 


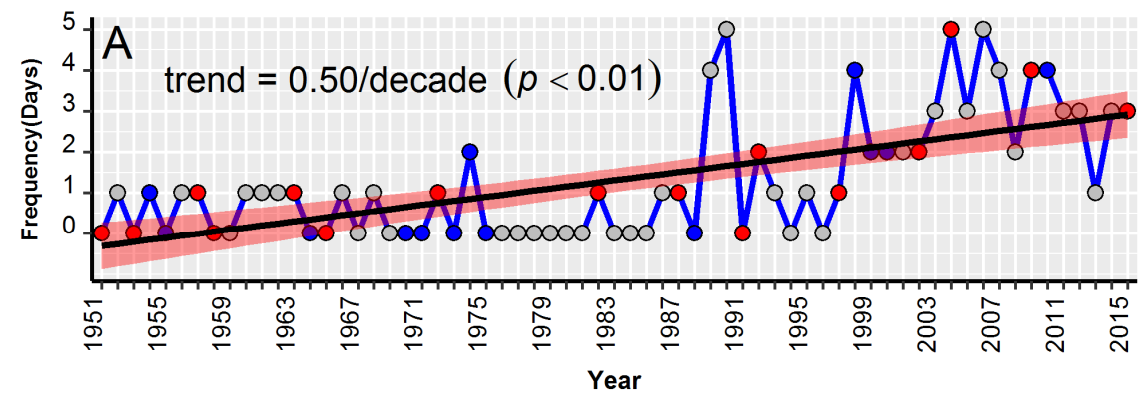

status

- El Nino year

- La Nina year

- Neutral year

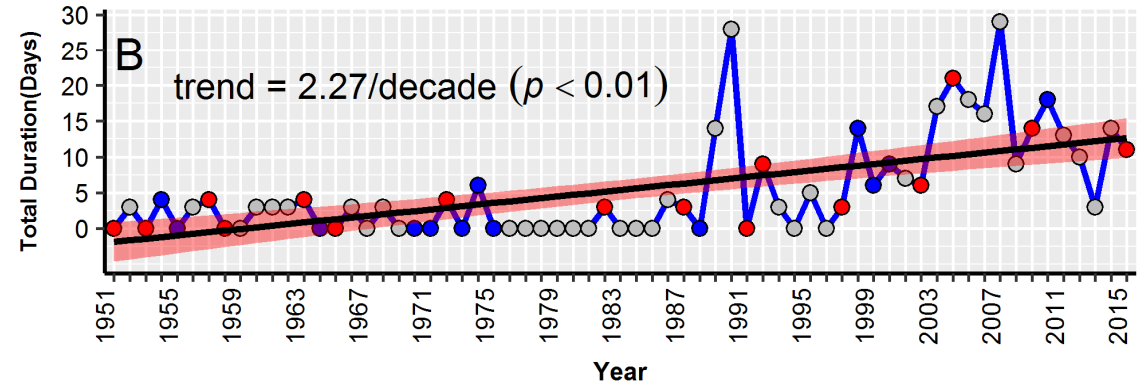

status

- El Nino year

- La Nina year

- Neutral year

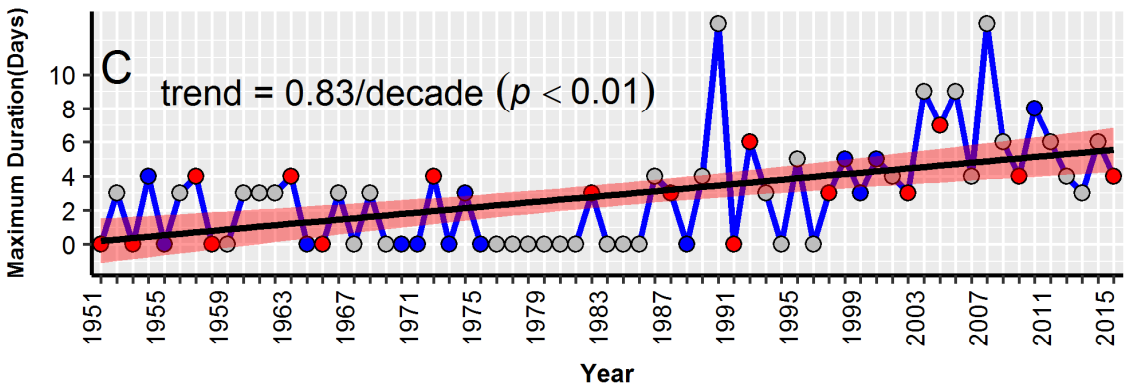

status

- El Nino year

- La Nina year

- Neutral year

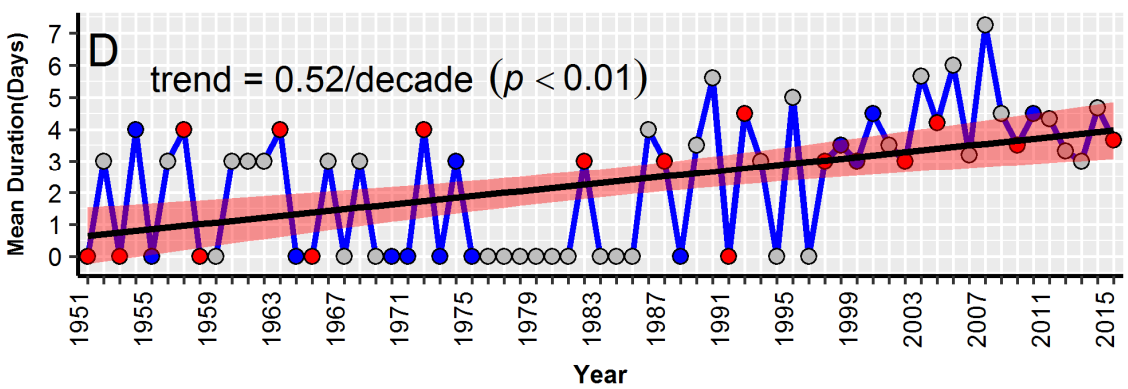

status

- El Nino year

- La Nina year

- Neutral year

Figure 3. Annual time series of frequency and duration of heat waves in Guangzhou during 1951-2015. (A) Frequency; (B) total duration; (C) maximum duration and (D) mean duration. The linear trend line (black line) and the corresponding 95\% confidence intervals (the shaded areas) are also shown. The solid dots in different colors show the occurrence of El Niño years, La Niña years and Neutral years. 


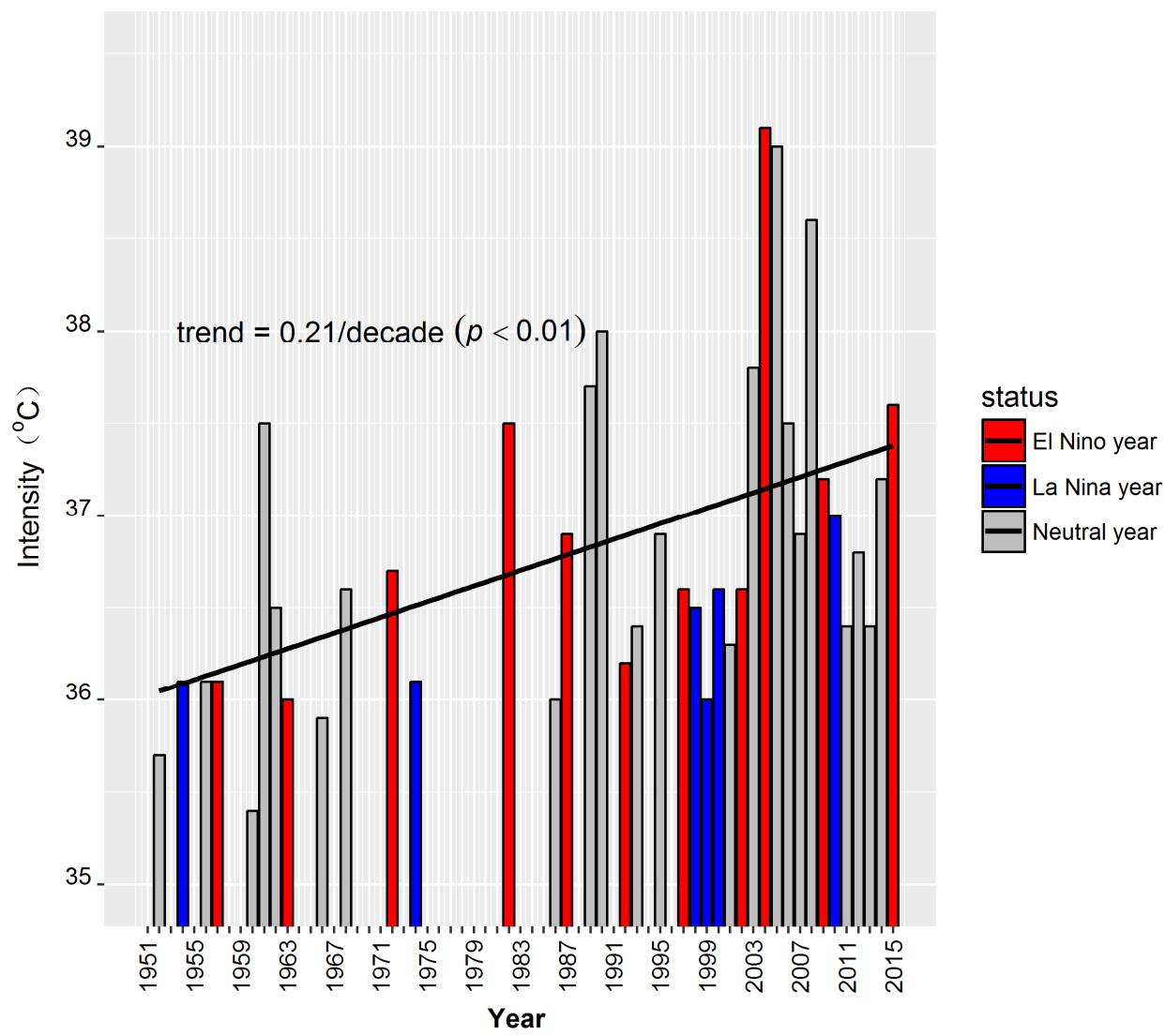

Figure 4. The intensity of heat waves in Guangzhou during 1951-2015. Annual intensity indicates the maximum value of daily maximum temperature during all heat waves in the year. The color of each bar shows the occurrence of El Niño years, La Niña years or Neutral years.

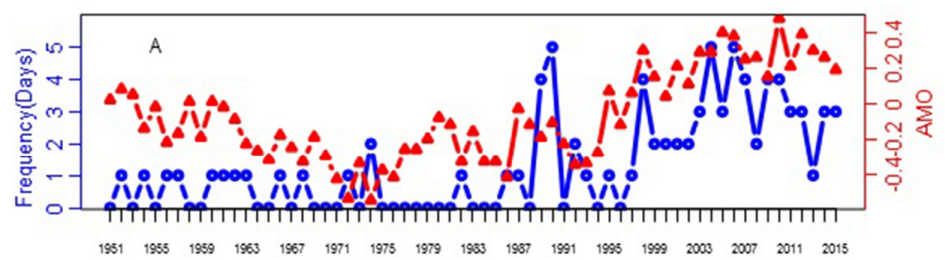

year

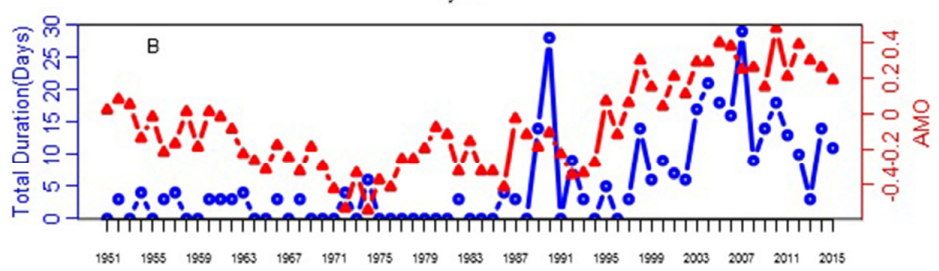

year

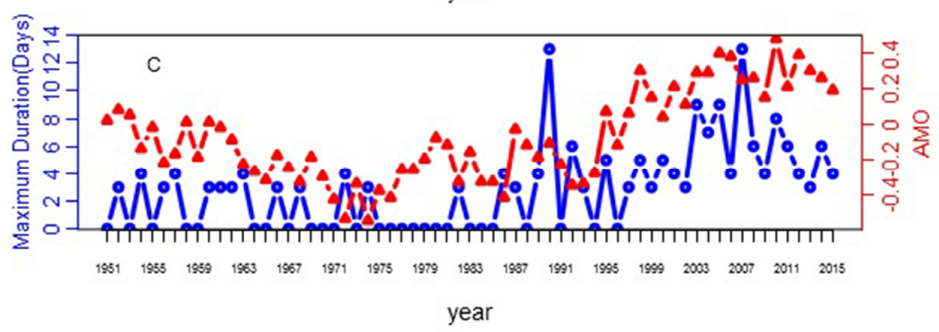

Figure 5. Cont. 


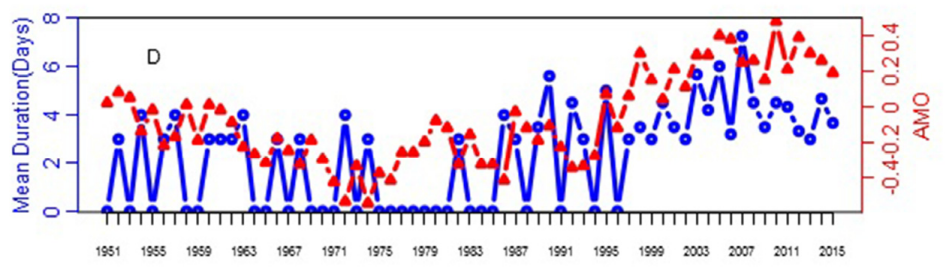

year

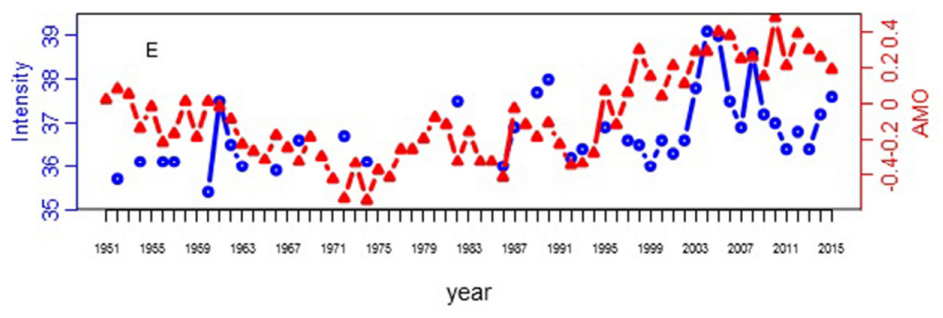

Figure 5. The time series of annual Atlantic Multi-decadal Oscillation (AMO) and annual frequency (A), total duration (B), maximum duration (C), mean duration (D) and intensity (E) of heat waves.

For the total of 14 cold spells observed during 1951-2015, the mean duration was 8.18 days and the longest duration was 17 days in January 1969. The coldest day of cold spells occurred on 29 December 1991 with a minimum temperature of $0.90{ }^{\circ} \mathrm{C}$. The variation trend of frequency, duration and intensity of cold spells is shown in Figures 6 and 7. The annual frequency, mean duration and intensity of cold spells did not show a significant linear trend at the 95\% confidence level ( $p=0.15,0.25$ and 0.41 , respectively). Besides, the result of ANOVA indicated that there were no significant differences in frequency, mean duration and intensity of cold spells among El Niño years and La Niña years and Neutral years ( $p=0.08,0.21$ and 0.80 , respectively). We did not find a significant linear correlation between annual AMO and the frequency, mean duration and intensity of cold spells $(p=0.36,0.21$ and 0.88 , respectively). No associations were observed between IOBW and the characteristics of cold spells $(p=0.31,0.21$ and 0.48 , respectively).

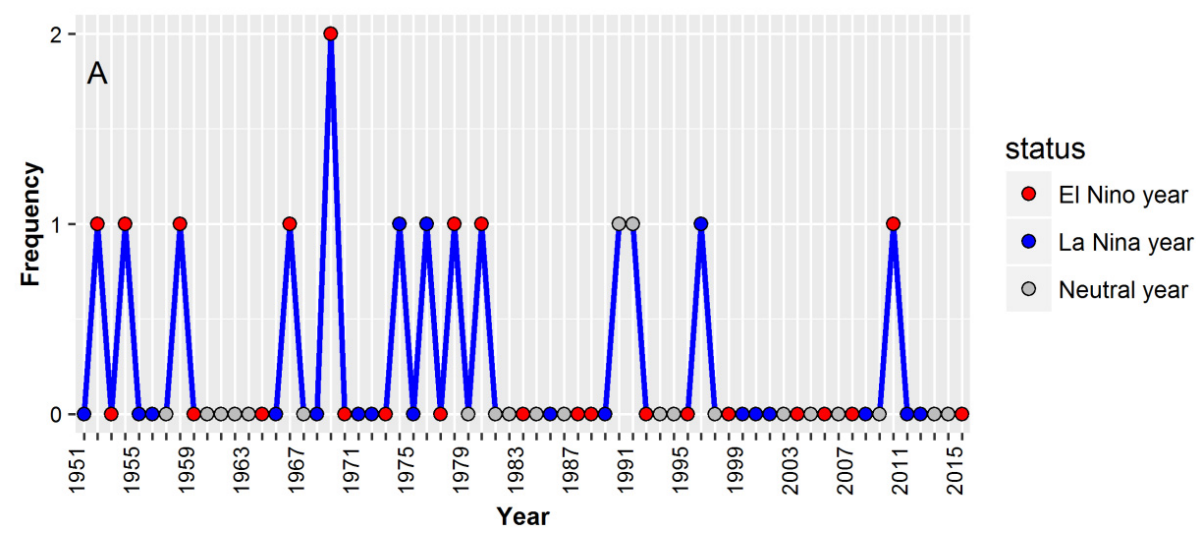

Figure 6. Cont. 


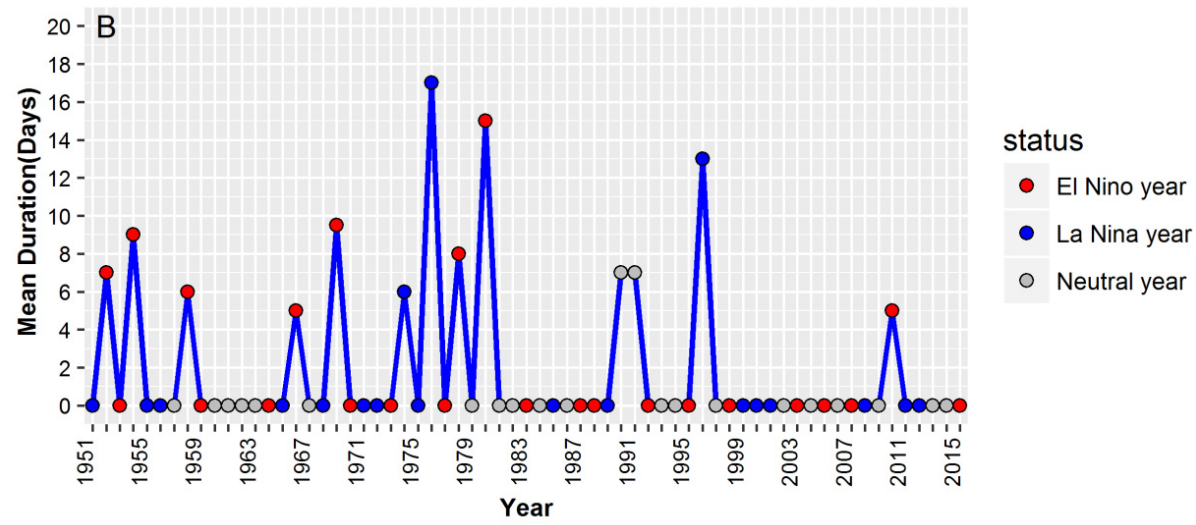

Figure 6. Time series of (A) frequency (B) mean duration (days) of Cold Spells in Guangzhou during 1951-2015. The solid dots in different colors show the occurrence of El Niño years, La Niña years and Neutral years. The index of total duration and maximum duration of cold spells was ignored due to only one or two cold spells per year.

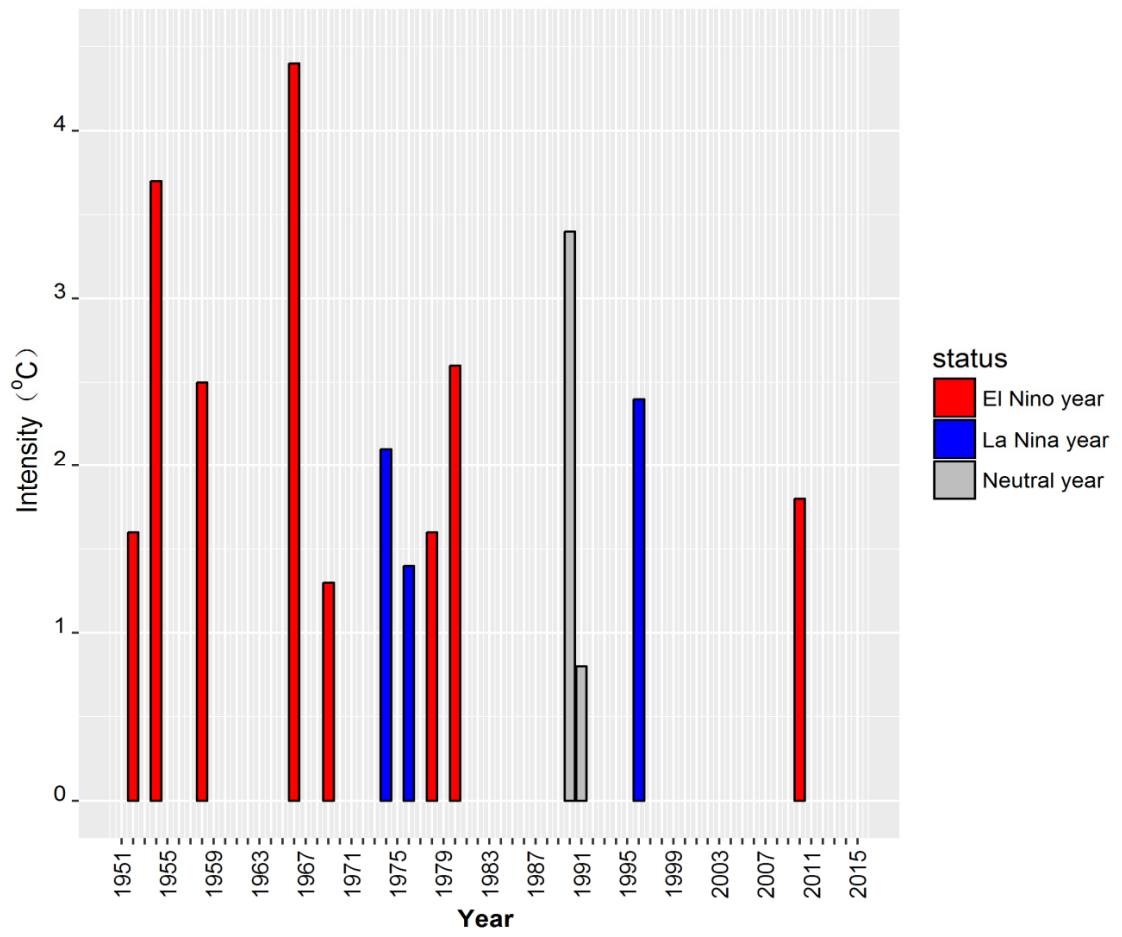

Figure 7. The intensity of cold spells in Guangzhou during 1951-2015. Annual intensity indicates the minimum value of daily minimum temperature during all cold spells in the year. The color of each bar shows the occurrence of El Niño years, La Niña years or Neutral years.

\section{Discussion}

In this study, we examined the trend of heat waves and cold spells in Guangzhou over a long period of 65 years. Additionally, we analyzed the correlation between heat waves/cold spells and ENSO events based on the data collected over the several past decades in China, where the correlation is speculated to be higher compared to other regions [34]. Moreover, the correlations between $\mathrm{AMO} / \mathrm{IOBW}$ and the characteristics of heat waves, including frequency, duration and intensity, were explored. 
During the study period, we observed an increase rate of $0.14{ }^{\circ} \mathrm{C}$ per decade in the annual mean temperature in Guangzhou, which was higher than both the national rate $\left(0.09-0.15^{\circ} \mathrm{C} /\right.$ decade $)$ and the global rate $\left(0.064^{\circ} \mathrm{C} /\right.$ decade) reported in the Third National Assessment Report on Climate Change in China [35] and the Fifth Assessment Report of the Intergovernmental Panel on Climate Change [1]. We found annual extreme warm days increased by 6.26 days per decade while annual extreme cold days decreased by 1.77 days per decade. The increase in temperature may be explained by the continued decrease of the Arctic ice in the last 35 years (1979-2013), which resulted in the warming and moistening of the lower troposphere and increases in cloud cover and precipitation, and had remote impacts on mid-latitude weather changes [36,37]. The variations of net solar radiation may also be related to the decrease in annual minimum temperature [19,38]. Particularly, urbanization, with increasing air pollution aerosols and urban albedo, partly explains the increasing trend of annual maximum temperature in the urbanized areas.

We observed an obvious increase in various aspects of heat waves including annual frequency, total duration, maximum duration, mean duration and intensity in Guangzhou. Some previous studies also reported an increasing trend of frequency and duration of heat waves in Southwest China, China, Indian and Australia [13-15,39]. However, it is worth mentioning that Ye et al. [15] reported a decreasing trend of intensity from the early 1960s to the mid-1980s and a significant increasing trend from the early 1990s to 2010 in China. By contrast, Ma et al. [39] found a decrease trend of the intensity in Southwest China during 1961-2010 and Boschat's study in India did not observe significant trends in the intensity of heat waves [40]. Different regions, climate conditions, study periods, and definitions of intensity may result in the inconformity about the variation of heat wave intensity. It is worth mentioning that the detrended data (i.e., subtracting a temperature of $0.14{ }^{\circ} \mathrm{C}$ per decade) still resulted in a significant increase in the duration and intensity of heat waves $(p<0.05)$, indicating that the increase in heat waves cannot only be explained by the shift of probability distribution of temperature to the right but is also attributed to increasing variations.

Similar to Boschat's study in India, there was no apparent association between the characteristics of heat waves and ENSO events in our study [40]. Some studies have suggested the delayed effects of ENSO events on climate anomalies in China $[20,33,34]$. Heat waves may be not related to concurrent ENSO events, because of the lag between the responses in atmospheric circulation to the change in the sea surface temperature. Many studies have indicated the connection between heat waves and the sea surface temperature. In addition, a correlation between the sea surface temperature and the diurnal temperature range (DTR) and precipitation has been reported previously [41-44]. Consistent with the findings over the Northern Hemisphere and Arabic regions [41,45], significant correlations between the characteristics of heat waves and AMO/IOBW were found in our study, probably because all the variables showed an increasing trend. This explanation was proved by the fact that the linearly detrended data did not exhibit such correlation.

It was obvious that cold spell events were sparser than heat wave events in Guangzhou. The subtropical monsoon climate, global warming and the acceleration of urbanization result in fewer cold days in Guangzhou. Similar to the cold spell study in Hong Kong [32], no statistically significant relationship between annual frequency, mean duration and intensity of cold spells and ENSO events was found. However, we observed 9 cold spells in 24 El Niño years as compared to 3 in 19 La Niña years and 2 in 22 Neutral years. Cold spells in Guangzhou may be likely to happen in El Niño years with a marginal significance $(p=0.08)$.

There are some issues that need further study. Firstly, we only analyzed the association between air temperature and ENSO events. In the next step, our research scope will be extended to the air pollutants, rainfall, droughts, or even parasitic diseases such as malaria, chickenpox in the whole of China, even Southeast Asia. Secondly, considering the integrity of the data, the ocean data from two countries were used in our study. This could cause heterogeneity in the original data. Thirdly, we examined the long-term trends of heat waves and cold spells during the whole study period of 65 years. It would be interesting to further explore whether the variation trend of the characteristics 
of climate events changes over time. Lastly, we did not identify effects of ENSO events on heat waves in the concurrent year, while we cannot ignore the possibility of delayed effects.

\section{Conclusions}

The number of annual extreme warm days increased and annual extreme cold days decreased significantly during the past 65 years in Guangzhou, China. There was a consistent increasing trend of frequency, duration and intensity of heat waves. We revealed significant positive correlations between annual $\mathrm{AMO} / \mathrm{IOBW}$ and the frequency, duration and intensity of heat waves. However, there was no obvious trend of cold spells. In addition, we did not observe significant differences in characteristics of heat waves/cold spells among El Niño years and La Niña years and Neutral years. Our study contributes to better understanding of the trend of extreme temperatures. Moreover, the findings in our study would help to develop reasonable policies for coping with heat waves/cold spells.

Acknowledgments: This work was supported by the National Nature Science Foundation of China (81573249 and 81402758) and Natural Science Foundation of Guangdong Province (2016A030313530). We thank Xin-Rui Ma, Chen-Jian Qian, Jin Li, Qiong-Bin Wang and Jie-Qi Jin for their assistance in cleaning and analyzing data.

Author Contributions: Chun-Quan Ou and Yan Zhuang initiated and designed the study. Rong Zhang and Zhao-Yue Chen collected and analyzed the data. Rong Zhang and Yan Zhuang drafted the manuscript. All authors reviewed and approved the final manuscript.

Conflicts of Interest: The authors declare no conflict of interest.

\section{References}

1. Stocker, T.F.; Qin, D.; Plattner, G.K.; Tignor, M.; Allen, S.K.; Boschung, J.; Nauels, A.; Xia, Y.; Bex, B.; Midgley, B.M. Climate Change 2013: The Physical Science Basis; Cambridge University Press: London, UK, 2013; pp. 161-162.

2. Thamo, T.; Addai, D.; Pannell, D.J.; Robertson, M.J.; Thomas, D.T.; Young, J.M. Climate change impacts and farm-level adaptation: Economic analysis of a mixed cropping-livestock system. Agric. Syst. 2017, 150, 99-108. [CrossRef]

3. Huang, C.; Barnett, A.G.; Wang, X.; Vaneckova, P.; Fitzgerald, G.; Tong, S. Projecting Future Heat-Related Mortality under Climate Change Scenarios: A Systematic Review. Environ Health Perspect. 2011, 119, 1681-1690. [CrossRef] [PubMed]

4. Johnson, R.G.; Kandeh, M.; Jalloh, A.; Nelson, G.C.; Thomas, T.S. Sierra leone. In West African Agriculture and Climate Change: A Comprehensive Analysis; Jalloh, A., Nelson, G.C., Thomas, T.S., Zougmoré, R.B., Roy-Macauley, H., Eds.; International Food Policy Research Institute: Washington, DC, USA, 2015.

5. White, B. Climate Change: Impacts, Adaptation, and Vulnerability; Cambridge University Press: London, UK, 2010.

6. Meehl, G.A.; Tebaldi, C.; Walton, G.; Easterling, D.; Mcdaniel, L. Relative increase of record high maximum temperatures compared to record low minimum temperatures in the U.S. Geophys. Res. Lett. 2009, 36, 110-125. [CrossRef]

7. Dash, S.K.; Mamgain, A. Changes in the Frequency of Different Categories of Temperature Extremes in India. J. Appl. Meteorol. Clim. 2011, 50, 1842-1858. [CrossRef]

8. Sigmond, M.; Reader, M.C.; Fyfe, J.C.; Gillett, N.P. Drivers of past and future Southern Ocean change: Stratospheric ozone versus greenhouse gas impacts. Geophys. Res. Lett. 2011, 38. [CrossRef]

9. Qian, W.; Wu, K.; Leung, J.C. Three-dimensional structure and long-term trend of heat wave events in western Eurasia revealed with an anomaly-based approach. Int. J. Climatol. 2016, 36, 4315-4326. [CrossRef]

10. Cohen, J.; Screen, J.A.; Furtado, J.C.; Barlow, M.; Whittleston, D.; Coumou, D.; Francis, J.; Dethloff, K.; Entekhabi, D.; Overland, J. Recent Arctic amplification and extreme mid-latitude weather. Nat. Geosci. 2014, 7, 627-637. [CrossRef]

11. Schubert, S.D.; Wang, H.; Koster, R.D.; Suarez, M.J.; Groisman, P.Y. Northern Eurasian heat waves and droughts. J. Clim. 2014, 27, 3169-3207. [CrossRef]

12. Allen, S.M.J.; Gough, W.A.; Mohsin, T. Changes in the frequency of extreme temperature records for Toronto, Ontario, Canada. Theor. Appl. Climatol. 2015, 119, 481-491. [CrossRef] 
13. Perkins, S.E.; Alexander, L.V. On the Measurement of Heat Waves. J. Clim. 2013, 26, 4500-4517. [CrossRef]

14. Rohini, P.; Rajeevan, M.; Srivastava, A.K. On the Variability and Increasing Trends of Heat Waves over India. Sci. Rep. UK 2016, 6, 26153. [CrossRef] [PubMed]

15. Ye, D.-X.; Yin, J.-F.; Chen, Z.-H.; Zheng, Y.-F.; Wu, R.-J. Spatial and Temporal Variations of Heat Waves in China from 1961 to 2010. Adv. Clim. Chang. Res. 2014, 5, 66-73.

16. Luo, D.; Xiao, Y.; Yao, Y.; Dai, A.; Simmonds, I.; Franzke, C.L.E. Impact of Ural Blocking on Winter Warm Arctic-Cold Eurasian Anomalies. Part I: Blocking-Induced Amplification. J. Clim. 2016, 29, 3925-3947. [CrossRef]

17. Luo, D.; Xiao, Y.; Diao, Y.; Dai, A.; Franzke, C.L.E.; Simmonds, I. Impact of Ural Blocking on Winter Warm Arctic-Cold Eurasian Anomalies. Part II: The Link to the North Atlantic Oscillation. J. Clim. 2016, 29, 3949-3971. [CrossRef]

18. Hou, Y.-L.; Chen, B.-D.; Yang, X.-C.; Liang, P. Observed Climate Change in East China during 1961 to 2007. Adv. Clim. Chang. Res. 2013, 4, 84-91.

19. Zhang, Q.; Li, J.; Chen, Y.D.; Chen, X. Observed changes of temperature extremes during 1960 to 2005 in China: Natural or human-induced variations? Theor. Appl. Climatol. 2011, 106, 417-431. [CrossRef]

20. Wang, W.; Zhou, W.; Chen, D. Summer high temperature extremes in Southeast China: Bonding with the El Niño-Southern oscillation and East Asian summer monsoon coupled system. J. Clim. 2014, 27, 4122-4138. [CrossRef]

21. Wang, C.; Wang, X. Classifying El Niño Modoki I and II by different impacts on rainfall in Southern China and typhoon tracks. J. Clim. 2013, 26, 1322-1338. [CrossRef]

22. Li, X.; Zhou, W. Quasi-4-yr coupling between El Niño-Southern Oscillation and water vapor transport over East Asia-WNP. J. Clim. 2012, 25, 5879-5891. [CrossRef]

23. China Meteorological Data Network. Available online: http://data.cma.cn/data/index/6d1b5efbdcbf9a58. html (accessed on 20 December 2016).

24. Climate Prediction Center of National Oceanic and Atmospheric Administration. Available online: http://www.cpc.noaa.gov/products/analysis_monitoring/ensostuff/ensoyears.shtml (accessed on 20 December 2016).

25. Chinese National Climate Centre. Available online: http://cmdp.ncc-cma.net/Monitoring/cn_index_130. php (accessed on 20 December 2016).

26. Chinese National Climate Centre. Available online: http://cmdp.ncc-cma.net/download/precipitation/ diagnosis/IOBW/iobw-mon-history.tms (accessed on 20 December 2016).

27. Chen, S.; Chen, W.; Wei, K. Recent trends in winter temperature extremes in eastern China and their relationship with the Arctic Oscillation and ENSO. Adv Atmos. Sci. 2013, 30, 1712-1724. [CrossRef]

28. Peterson, T.C.; Zhang, X.; Brunet India, M.; Vázquez Aguirre, J.L. Changes in North American extremes derived from daily weather data. J. Geophys. Res. Atmos. 2008, 113. [CrossRef]

29. Efthymiadis, D.; Goodess, C.M.; Jones, P.D. Trends in Mediterranean gridded temperature extremes and large-scale circulation influences. Nat. Hazard. Earth Syst. 2011, 11, 2199-2214. [CrossRef]

30. Li, J.; Xu, X.; Ding, G.; Zhao, Y.; Zhao, R.; Xue, F.; Li, J.; Gao, J.; Yang, J.; Jiang, B.; et al. A Cross-Sectional Study of Heat Wave-Related Knowledge, Attitude, and Practice among the Public in the Licheng District of Jinan City, China. Int. J. Environ. Res. Public Health 2016, 13, 648. [CrossRef] [PubMed]

31. Huang, W.; Kan, H.; Kovats, S. The impact of the 2003 heat wave on mortality in Shanghai, China. Sci. Total Environ. 2010, 408, 2418-2420. [CrossRef] [PubMed]

32. Wu, M.C.; Leung, W.H. Effect of ENSO on the Hong Kong winter season. Atmos. Sci. Lett. 2009, 10, 94-101. [CrossRef]

33. Bao, M.; Han, R. Delayed impacts of the El Niño episodes in the central Pacific on the summertime climate anomalies of eastern China in 2003 and 2007. Adv. Atmos. Sci. 2009, 26, 553-563. [CrossRef]

34. Malhi, Y.; Wright, J. Spatial patterns and recent trends in the climate of tropical rainforest regions. Philos. Trans. R. Soc. B Biol. Sci. 2004, 359, 311-329. [CrossRef] [PubMed]

35. Peng, W. The Third National Assessment Report on Climate Change. 2015. Available online: http://www. cma.gov.cn/en2014/news/News/201511/t20151123_298038.html (accessed on 20 December 2016).

36. Simmonds, I. Comparing and contrasting the behaviour of Arctic and Antarctic sea ice over the 35 year period 1979-2013. Ann. Glaciol. 2015, 56, 18-28. [CrossRef] 
37. Screen, J.A.; Deser, C.; Simmonds, I.; Tomas, R. Atmospheric impacts of Arctic sea-ice loss, 1979-2009: Separating forced change from atmospheric internal variability. Clim. Dynam. 2014, 43, 333-344. [CrossRef]

38. Boschat, G.; Pezza, A.; Simmonds, I.; Perkins, S.; Cowan, T.; Purich, A. Large scale and sub-regional connections in the lead up to summer heat wave and extreme rainfall events in eastern Australia. Clim. Dynam. 2015, 44, 1823-1840. [CrossRef]

39. Ma, Z.F.; Liu, J.; Zhang, S.Q.; Chen, W.X.; Yang, S.Q. Observed Climate Changes in Southwest China during 1961-2010. Adv. Clim. Chang. Res. 2013, 4, 30-40. [CrossRef]

40. Boschat, G.; Simmonds, I.; Purich, A.; Cowan, T.; Pezza, A.B. On the use of composite analyses to form physical hypotheses: An example from heat wave-SST associations. Sci. Rep. UK 2016, 6, 29599. [CrossRef] [PubMed]

41. Donat, M.G.; Peterson, T.C.; Brunet, M.; King, A.D.; Almazroui, M.; Kolli, R.K.; Boucherf, D.; Al-Mulla, A.Y.; Nour, A.Y.; Aly, A.A. Changes in extreme temperature and precipitation in the Arab region: Long-term trends and variability related to ENSO and NAO. Int. J. Climatol. 2014, 34, 581-592. [CrossRef]

42. Li, Y.; Wu, B.; Yang, Q.; Huang, S. Different relationships between spring SST in the Indian and Pacific oceans and summer precipitation in China. Acta Meteorol. Sin. 2013, 27, 509-520. [CrossRef]

43. Kim, B.; Ha, K. Observed changes of global and western Pacific precipitation associated with global warming SST mode and mega-ENSO SST mode. Clim Dynam. 2015, 45, 3067-3075. [CrossRef]

44. Brown, J.N.; Matear, R.J.; Brown, J.R.; Katzfey, J. Precipitation projections in the tropical Pacific are sensitive to different types of SST bias adjustment. Geophys. Res. Lett. 2015, 42, 10856-10866. [CrossRef]

45. Zhou, C.; Wang, K. Coldest Temperature Extreme Monotonically Increased and Hottest Extreme Oscillated over Northern Hemisphere Land during Last 114 Years. Sci. Rep. UK 2016, 6, 25721. [CrossRef] [PubMed]

(C) 2017 by the authors; licensee MDPI, Basel, Switzerland. This article is an open access article distributed under the terms and conditions of the Creative Commons Attribution (CC BY) license (http:/ / creativecommons.org/licenses/by/4.0/). 